\title{
Hospice Nurses' Knowledge and Attitudes Toward the Near-Death Experience
}

\author{
Linda Barnett, R.N., C.C.R.N., M.S.N. \\ Radford University
}

ABSTRACT: I surveyed 60 hospice nurses regarding their knowledge and attitudes toward the near-death experience (NDE), using Thornburg's NearDeath Phenomena Knowledge and Attitudes Questionnaire. Most hospice nurses had previous work experience with an NDEr. Approximately half the nurses were knowledgeable about the NDE. All participants had a positive attitude toward near-death phenomena and toward caring for an NDEr. Recommendations include near-death phenomena inservice education for hospice nurses and inclusion of NDE content in nursing education programs.

The near-death experience (NDE) is a topic of increasing controversial concern, especially among paraprofessionals and health care professionals providing holistic care to the terminally ill client. The NDE can be summarized as a close encounter with death having sequential components that culminate in a spiritual event. Thus this spiritual event encompasses physiological involvement, a mental metamorphosis, and an apparent encounter with a spiritual being (Moody, 1975; Ring, 1984; Moody and Perry, 1988).

Advancements in medical technology have provided the means for a significant number of acute care and terminally ill clients to be resuscitated (Grosso, 1981). Thus the NDE is experienced by a variety of clients with acute health dysfunctions as well as by a majority of clients with terminal and chronic illnesses (Kübler-Ross, 1975; Ring,

Ms. Barnett is a critical care staff nurse in the Baptist Medical Center Medical Intensive Care Unit in San Antonio, TX. This paper was derived in part from her Master of Science in Nursing thesis submitted to Radford University. Reprint requests should be addressed to Ms. Barnett at 223 Harcourt, San Antonio, TX 78223. 
1984). Nurses providing care to such clients need adequate knowledge and attitudes in order to help clients deal with their emotional and spiritual feelings about the dying process and/or the NDE.

Since hospital stays have shortened, many terminally and chronically ill clients have been ushered into the community where care is continued. Hospice nurses constitute a majority of home supportive caregivers, and it is these nurses who are present to provide the holistic care and spiritual support these clients require.

The NDE is a spiritual event with significant implications for the terminally ill client, who may or may not have experienced near-death phenomena. Furthermore, the NDE needs to be recognized and understood by hospice nurses who care for terminally ill clients, as this phenomenon may be incorporated into the holistic approach of the hospice nurse by providing a positive counseling strategy for those clients who may be afraid of death or who may have questions regarding the dying process. This study was designed to assess the knowledge and attitudes of hospice nurses toward the near-death experience and toward caring for near-death experiencers.

\section{Theoretical Framework and Review of the Literature}

The theoretical framework for this study was based on Jean Watson's (1988) model of human care. According to Watson, the main goal of nursing is to help individuals attain and maintain a higher level of accord within their consciousness, physical being, and spiritual essence. Within Watson's theory, the actual caring occasion is a phenomenal field that identifies the role of both the hospice nurse and the hospice client. These two persons, the hospice nurse and the hospice client, with their unique pasts and spiritual personal histories, constitute an event within the phenomenal field.

Thus the actual caring occasion is a phenomenal field that incorporates time and space in which life's experiences, knowledge, and attitudes take place, including near-death phenomena. Providing counseling to terminally ill clients regarding the dying process and the NDE is an actual caring occasion that provides a hospice nurse a positive interactional (transpersonal) linkage to the client and his or her family.

The scientific literature has documented the existence of a neardeath phenomenal event composed of specific spiritual components. The client who has experienced a near-death phenomenal event reports a more positive attitude toward life, a sense of invulnerability, a 
sense of destiny, an increased belief in continued spiritual existence after bodily death, and a decreased fear of dying (Ring, 1980; Grosso, 1981; Greyson, 1983; Royse, 1985). Newly discovered knowledge about NDEs may be useful for informing terminally ill clients and their families who have questions or fears concerning dying and the grieving process (Ring, 1982).

There have been only a few studies that assessed the knowledge of and attitudes toward NDEs among health care professionals, and no research studies that assessed the knowledge and attitudes of hospice nurses toward the NDE. Ron Hammond (1989) discussed the importance of educating emergency medical technicians, who provide care to clients in an emergency situation, regarding near-death phenomena.

Nina Thornburg (1988) conducted a study to pilot test her research instrument, the Near-Death Phenomena Knowledge and Attitudes Questionnaire, and to assess the knowledge of and attitudes toward NDEs of 20 critical care nurses at a large Midwestern medical center. Ninety-five percent of her subjects responded that they had heard of NDEs, but none indicated that they personally had undergone a neardeath experience.

Barbara Walker and Robert Russell (1988) surveyed the knowledge and attitudes of 117 randomly selected psychologists, using Thornburg's Near-Death Phenomena Knowledge and Attitudes Questionnaire. Their results indicated a high number of positive attitudes toward NDEs among the participants. Seven percent of their respondents indicated that they had personally had an NDE, and 19 percent indicated that they had counseled near-death experiencers (NDErs).

Despite the relevance of near-death phenomena for terminally ill clients and their families, no study has yet investigated knowledge and attitudes of hospice nurses toward the NDE. The purpose of this study was to expand research into near-death phenomena by assessing hospice nurses' knowledge and attitudes using Thornburg's Near-Death Phenomena Knowledge and Attitudes Questionnaire.

\section{Method}

\section{Sample and Procedure}

I distributed 111 questionnaires, along with a cover letter, to nurses employed at hospice agencies that were members of the Virginia Association of Hospice, during the nurses' working hours at a time prear- 
ranged by the Hospice Coordinator. Informed consent was obtained from participants, and anonymity was guaranteed. I provided selfaddressed stamped envelopes for nurses who wished to participate but were unable to do so at the time I visited their particular agency. Two weeks following my visit to each hospice agency, I sent a thank you note to that agency, reminding those nurses who had not yet returned their questionnaires to do so. I received 60 completed questionnaires, for a 55 percent return rate.

\section{Data Collection and Analysis}

The data collection instrument for this study was a questionnaire composed of two sections. The first section consisted of demographic questions exploring gender, age, level of nursing position, employment status, educational level, religious preference, and prior experience with a client who had undergone an NDE. The second section consisted of Thornburg's (1988) Near-Death Phenomena Knowledge and Attitudes Questionnaire, composed of (a) 23 true/false/undecided response items assessing knowledge, (b) 23 Likert scale items assessing general attitudes toward near-death phenomena, and (c) 20 Likert scale items assessing attitude toward caring for a client who has had an NDE.

For the purposes of this study, the following scoring procedures were utilized. For the knowledge section of Thornburg's knowledge and attitudes scale, a value of 1 was assigned for correct responses, and a value of 0 was assigned for incorrect or "undecided" responses. Participants who scored 12 or more points, out of a possible total of 23 , were considered knowledgeable about near-death phenomena.

For the sections assessing general attitudes toward near-death phenomena and attitudes toward caring for an NDEr, responses were rated on a five-point scale ranging from $1=$ "strongly agree" to $5=$ "strongly disagree." For the general attitudes section, a score of 69 or more points, out of a possible total of 115 , was taken to indicate a positive attitude toward NDEs. For the section assessing attitudes toward caring for an NDEr, a score of 60 or more points, out of a possible total of 100 , was taken to represent a positive attitude toward caring for a client who has had an NDE.

I used descriptive statistics, including percentages, means, standard deviations, and standard errors, to analyze responses representing hospice nurses' knowledge and attitudes toward near-death phenomena and NDErs. 


\section{Results}

\section{Demographics}

Of the 60 nurses who returned completed questionnaires, 57 (95 percent) were female, and the age range was 26 to 67 years, with a mean age of 42.3 years. Thirty-four study participants ( 57 percent) were employed full-time, and 36 ( 60 percent) had a baccalaureate or higher degree. Thirty-eight respondents (63 percent) reported having worked with a client who had experienced an NDE, and one hospice nurse ( 2 percent) reported that she personally had had an NDE. The largest proportion of study participants, 35 (58 percent), were of the Protestant faith.

\section{Knowledge of Near-Death Phenomena}

Thirty-one (52 percent) of the respondents were found to be adequately knowledgeable about near-death phenomena, as judged by scoring 12 or more points on the knowledge section of the scale. Of those nurses who were adequately knowledgeable about NDEs, the majority could identify the components of the NDE, knew that some element unrelated to medication produces NDEs, and believed that the NDE points toward a spiritual afterlife. Table 1 lists mean scores on the knowledge section of the scale along with standard deviation, range, and standard error, based on nurses' educational level.

\section{General Attitudes Toward Near-Death Phenomena}

All 60 respondents indicated a positive attitude toward the NDE, as judged by a score of 69 or more points on the general attitudes section of the scale; participants' mean score was 92.18. A majority of respondents indicated that stories about near-death phenomena did not frighten them and agreed that they should have open dialogue with their clients regarding NDEs and that appropriate documentation should be reflected in the client's medical record. Many respondents felt that clients who have had NDEs should be invited to relate their experiences to staff in inservice education conferences. Furthermore, study participants indicated that a course dealing with near-death phenomena should be included in the curriculum for nursing students. 


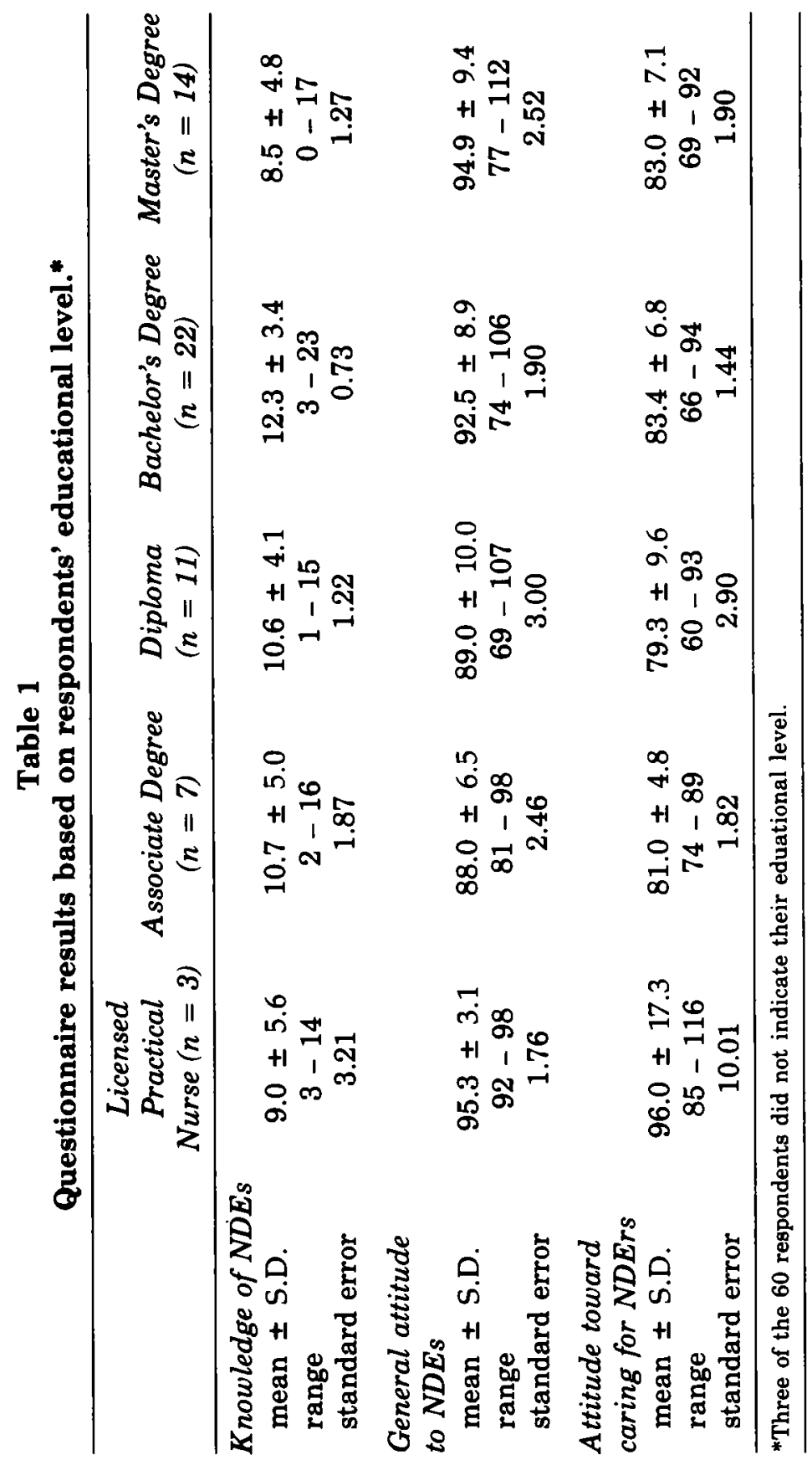


Table 1 lists responses on the general attitudes section based on nurses' educational level.

\section{Attitude Toward Caring For a Near-Death Experiencer}

All 60 respondents indicated a positive attitude toward caring for a client who has had an NDE, as judged by a score of 60 more points on the attitude toward caring for an NDEr section of the scale; participants' mean score was 83.08. A majority of the participants believed that they should listen attentively to an NDEr's report, allowing the client to complete his or her story, and agreed that these clients should receive the same quality care as other clients who have not experienced an NDE. Furthermore, two-thirds of the respondents indicated that they would like to work with a client who had undergone an NDE. Table 1 lists the responses on the attitude toward caring section of the scale based on nurses' educational level.

\section{Discussion}

These data reveal that hospice nurses are aware of the NDE and that they have a positive regard and respect for the phenomenon and for those clients who experience NDEs. Perhaps more important, hospice nurses feel that the NDE is a phenomenon of legitimate clinical concern and that discussing near-death phenomena may prove helpful as a positive counseling approach in working with terminally ill clients. Furthermore, hospice nurses are interested in attending inservice educational programs that would provide information about NDEs and agreed that near-death phenomena should be included in the curriculum for nursing students.

Study participants may have indicated such a positive response regarding inclusion of near-death phenomena in nursing educational program for three reasons: first, because they perceive it as a topic of increasing awareness, importance, and concern among terminally ill clients and their families; second, because they recognize the NDE as a component of the holistic spiritual care they deliver to their terminally ill clients and their families; and third, perhaps because of a lack of discussion about near-death phenomena in the current nursing educational curriculum.

The findings of this study suggest the need to recommend and develop more curriculum and instructional material regarding NDEs 
and to incorporate these materials into undergraduate nursing preparation. Furthermore, findings suggest that hospice nurses are interested in attending inservice conferences that focus on the NDE. Finally, hospice agencies should consider utilizing discussions of neardeath phenomena as another positive counseling approach in providing spiritual supportive care to terminally ill clients and their families.

Recommendations for future studies include replication of this study utilizing a larger population of hospice nurses or utilizing nursing education professors to determine their knowledge and attitudes toward the NDE. Finally, I would recommend a study that would focus on the relationship between knowledge about near-death phenomena and attitudes toward the NDE and caring for clients who report these experiences.

\section{References}

Greyson, B. (1983). The psychodynamics of near-death experiences. Journal of Nervous and Mental Disease, 171, 376-381.

Grosso, M. (1981). Toward an explanation of near-death phenomena. Anabiosis: The Journal of Near-Death Studies, 1, 3-26.

Hammond, R. (1989). Near-death experiences: Beyond the ordinary call. Journal of Emergency Medical Services, 14, 51-53.

Kübler-Ross, E. (1975). Death-the final stage of growth. Englewood Cliffs, NJ: PrenticeHall.

Moody, R.A. (1975). Life after life. Covington, GA: Mockingbird Books.

Moody, R.A., and Perry, P. (1988). The light beyond. New York, NY: Bantam.

Ring, K. (1980). Life at death: A scientific investigation of the near-death experience. New York, NY: Coward, McCann and Geoghegan.

Ring, K. (1982). Near-death studies: A new area of consciousness research. Storrs, CT: International Association for Near-Death Studies.

Ring, K. (1984). Heading toward omega: In search or the meaning of the near-death experience. New York, NY: William Morrow.

Royse, D. (1985). The near-death experience: A survey of clergy's attitudes and knowledge. Journal of Pastoral Care, 39, 31-42.

Thornburg, N. (1988). Development of the Near-Death Phenomena Knowledge and Attitudes Questionnaire. Journal of Near-Death Studies, 6, 223-238.

Walker, B.A., and Russell, R. (1989). Assessing psychologists' knowledge and attitudes toward near-death phenomena. Journal of Near-Death Studies, 8, 103-110.

Watson, J. (1988). Nursing: Human science and human care-a theory of nursing. New York, NY: National League for Nursing. 